\title{
RISK FACTORS OF HEPATITIS C INFECTION AMONG EGYPTIAN BLOOD DONORS
}

\author{
Hala Ibrahim Awadalla', Mostafa Hassan Ragab ${ }^{1}$, Nozat Ahmed Nassar ${ }^{3}$, Mahmoud Abd Hamid Osman² \\ ${ }^{1}$ Institute of Environmental Studies and Research, Ain Shams University, Cairo, Egypt \\ ${ }^{2}$ Faculty of Medicine, Ain Shams University, Cairo, Egypt \\ ${ }^{3}$ Faculty of Medicine, Cairo University, Cairo, Egypt
}

\begin{abstract}
SUMMARY
Background: Surveillance of infectious disease markers in the blood donor population is important in recognizing trends in prevalence and incidence of transfusion related infections in asymptomatic volunteer blood donors.

Subjects and Methods: It was a cross sectional study. Samples were collected from volunteer blood donors and questionnaire was designed to collect the risk factors data. The prevalence of hepatitis $\mathrm{C}$ antibodies among 1,000 apparently healthy blood donors were determined.

Objective: To estimate the prevalence of virus $\mathrm{C}$ hepatic infection and to illustrate the various socio-economic, behavioural and medical factors related to infection with Hepatitis $\mathrm{C}(\mathrm{HCV})$ among apparently healthy individuals. It contributed to analysis of the particularities of Egyptian blood donors and helped to better understand the challenges and solutions of blood safety.

Results: The prevalence of HCV was $16.8 \%$. There was an association of positive anti-HCV test with socio-demographic, medical and behavioural risk factors.

Conclusion: This study provided comprehensive and reliable information on the possible risk factors affecting spread of Hepatitis $\mathrm{C}$ in the area.
\end{abstract}

Key words: $\mathrm{HCV}$, risk factors, blood

Address for correspondence: H. I. Awadalla, Medical Science Department, Institute of Environmental Studies and Research, Ain Shams University, Abbassia Cairo 11566, Egypt. E-mail. Hala_Awadalla@yahoo.com

\section{INTRODUCTION}

Hepatitis C virus (HCV), first identified in 1989, is strictly a blood-borne RNA viral infection in the family Flaviviridae. Humans are the only reservoir for this viral infection (1). Despite that Hepatitis $\mathrm{C}$ is one of the most frequent infections associated with blood transfusion; it was the HIV epidemic that alerted general public to the importance of serological tests in blood banks (2). Hepatitis $C$ is a serious global public health problem. An estimated 170 million people were chronically infected with hepatitis $\mathrm{C}$ virus and 3-4 million people are newly infected each year (3). Available data suggest that only between $10 \%$ and $40 \%$ of people with $\mathrm{HCV}$ in Europe are aware of their infection (up to $90 \%$ of the prevalent pool are undiagnosed in such countries as Germany or Poland) (4).

The Middle East and North Africa region suffers from high prevalence of unnecessary medical injections and transfusions, reuse of needles and syringes, needle-stick injuries among health care workers, and skin scarifications (1). Hepatitis $\mathrm{C}$ is now recognized as the primary cause of transfusion associated with non A non B hepatitis. Hepatitis C is a major cause of chronic liver disease, including cirrhosis and liver cancer. Patients can live for many years without experiencing symptoms, and as a consequence, large number of cases remain undiagnosed. In more than $50 \%$ of infected individuals chronic hepatitis with serious and possibly life threatening sequel such as cirrhosis and hepatocellular carcinoma will develop (HCC) (5). About $80 \%$ of newly infected patients progress to develop chronic infection. Cirrhosis develops in about $10 \%$ to $20 \%$ of persons with chronic infection, and liver cancer develops in $1 \%$ to $5 \%$ of persons with chronic infection over a period of 20 to 30 years (6).

Numerous HCV prevalence studies in Egypt have published various estimates from different Egyptian communities, suggesting that Egypt, relative to the other nations of the world, might be experiencing intense ongoing $\mathrm{HCV}$ transmission (1).

In middle 20th-century Egypt, iatrogenic transmission of the hepatitis $\mathrm{C}$ virus occurred during the treatment of schistosomiasis with tartar emetic administered intravenously using hastily sterilized reusable syringes and needles (7). Egypt has a very high prevalence of $\mathrm{HCV}$ and high morbidity and mortality rates from chronic liver disease, cirrhosis, and hepatocellular carcinoma. Approximately $20 \%$ of Egyptian blood donors were anti-HCV positive (3).

\section{SUBJECTS AND METHODS}

This was a cross sectional study, the total number of blood donors tested was 1,000 subjects volunteered to donate blood in Kaser Al Ani hospital blood bank, Cairo, Egypt. To be eligible to donate blood, a person must be in good health and must be between $18-60$ years of age. Generally, donors must weigh at least 50 kilos. All donors must pass general and medical examinations prior to donation. Exclusion criteria include: younger or older 
ages, past history of jaundice, HIV, hypotension, anemia and severe chronic diseases. Before recruitment an informed consent was taken from every participant who agreed to be included in this study. Questionnaire was designed; it included questions concerning demographic (gender and age) and socioeconomic (education) aspects, detailed history of exposure to blood or blood products, social and sexual behaviour, and occupational hazard (unintentional needle-stick injuries, for instance), intravenous drug use, tattooing, acupuncture, surgery, personal history of jaundice or hepatitis or history of these diseases in the donor's family, previous hospitalization and parenteral administration of drugs.

Blood collected by venepuncture, serum or plasma might be used. An enzyme immunoassay for the detection of antibodies to Hepatitis C virus in human serum or plasma was used. Samples were incubated in micro wells coated with highly purified antigens of HCV. During the course of the first incubation, any anti HCV antibodies in the sample will bind to the immobilized antigens. Following washing to remove unbound material, the captured anti-HCV antibodies were incubated with peroxidase conjugated monoclonal anti-human IgG. A purple color developed in the wells which contained anti-HCV positive samples.

Statistical analysis: The collected data was organized and tabulated and statistically analyzed using SPSS for Windows version 13.0. Quantitative data was presented as mean \pm standard deviation (SD) and student t-test was used for statistical analysis. For qualitative data, the number and percentage distribution was calculated and chi-square test was applied for comparison. $\mathrm{p}<0.05$ was considered to indicate a significant difference.

\section{RESULTS}

Table 1 indicates that $16.8 \%$ of the studied sample were seropositive. It shows that the mean age of positive subjects (37.9) was higher than of negative subjects (30.4). It demonstrates the relation between $\mathrm{HCV}$ test results and the socio-demographic data of the studied group. This table shows that $15 \%$ of males and one quarter (25.1\%) of females were positive. More than half (57.1\%) of farmers were positive and more than one third of participants $(39.6 \%)$ who had jobs related to blood exposure were positive as well. Nearly three quarters $(71.1 \%)$ of illiterates were positive and all university graduated subjects were negative. Nearly one fifth $(21.6 \%)$ of low socio-economic level were positive.

Table 2 summarizes the medically related risk factors for $\mathrm{HCV}$ transmission; all factors were significantly associated with HCV transmission. It was found that nearly half (48.4\%) of those who had undergone surgical treatment were positive and nearly one third $(35.2 \%)$ of circumcised subjects by traditional healer were positive. Nearly three quarters $(72 \%)$ of subjects with history of blood transfusion were positive while nearly half $(52.7 \%)$ of those subjected to a used needle were positive. $81 \%$ of subjects who had received parenteral antischistosomal treatment were positive.

Table 3 demonstrates the behavioural related risk factors for HCV transmission. This table shows that $47.5 \%$ of drug abusers were positive, $30.1 \%$ of subjects having had ear piercing using common tools were also positive. There was no statistically significant difference related to sexual relations.

Table 1. Relation between HCV test results and socio-demographic characteristics of the studied subjects

\begin{tabular}{|c|c|c|c|c|c|c|c|}
\hline \multirow{3}{*}{\multicolumn{2}{|c|}{ Socio-demographic risk factors }} & \multicolumn{4}{|c|}{$\mathrm{HCV}$ test results } & \multirow{3}{*}{ test } & \multirow{3}{*}{$\mathrm{p}$-value } \\
\hline & & \multicolumn{2}{|c|}{ negative $(\mathrm{N}=832$ ) } & \multicolumn{2}{|c|}{ positive $(\mathrm{N}=168)$} & & \\
\hline & & $\mathrm{n}$ & $\%$ & $\mathrm{n}$ & $\%$ & & \\
\hline \multirow{2}{*}{ Gender } & Male & 701 & $85 \%$ & 124 & $15 \%$ & \multirow{2}{*}{$x^{2}=10.5$} & \multirow{2}{*}{0.001} \\
\hline & Female & 131 & $74.9 \%$ & 44 & $25.1 \%$ & & \\
\hline \multirow{7}{*}{ Occupation } & Laborers & 124 & $75.6 \%$ & 40 & $24.4 \%$ & \multirow{7}{*}{$X^{2}=286.3$} & \multirow{7}{*}{0.000} \\
\hline & Farmers & 57 & $42.9 \%$ & 76 & $57.1 \%$ & & \\
\hline & Managerial & 199 & $97.5 \%$ & 5 & $2.5 \%$ & & \\
\hline & Professionals & 49 & $100 \%$ & 0 & $.0 \%$ & & \\
\hline & House wife & 76 & $74.5 \%$ & 26 & $25.5 \%$ & & \\
\hline & Students & 295 & $100 \%$ & 0 & $.0 \%$ & & \\
\hline & Jobs related to- blood exposure & 32 & $60.4 \%$ & 21 & $39.6 \%$ & & \\
\hline \multirow{4}{*}{$\begin{array}{l}\text { Level } \\
\text { of education }\end{array}$} & Illiterate & 11 & $28.9 \%$ & 27 & $71.1 \%$ & \multirow{4}{*}{$x^{2}=236.8$} & \multirow{4}{*}{0.000} \\
\hline & Read write & 115 & $56.9 \%$ & 87 & $43.1 \%$ & & \\
\hline & Secondary & 570 & $91.3 \%$ & 54 & $8.7 \%$ & & \\
\hline & University & 136 & $100 \%$ & 0 & $.0 \%$ & & \\
\hline \multirow{2}{*}{ Marital status } & Married & 356 & $70.2 \%$ & 151 & $29.8 \%$ & \multirow{2}{*}{$x^{2}=124.01$} & \multirow{2}{*}{0.000} \\
\hline & Not & 476 & $96.6 \%$ & 17 & $3.4 \%$ & & \\
\hline \multirow{3}{*}{$\begin{array}{l}\text { Socio-economic } \\
\text { level }\end{array}$} & High level & 93 & $94.9 \%$ & 5 & $5.1 \%$ & \multirow{3}{*}{$x^{2}=38.3$} & \multirow{3}{*}{0.000} \\
\hline & Mid level & 191 & $94.1 \%$ & 12 & $5.9 \%$ & & \\
\hline & Low level & 548 & $78.4 \%$ & 151 & $21.6 \%$ & & \\
\hline \multicolumn{2}{|c|}{ Mean of age \pm std. deviation } & \multicolumn{2}{|c|}{$30.45 \pm 7.78$} & \multicolumn{2}{|c|}{$37.99 \pm 5.49$} & $t=11.9$ & 0.000 \\
\hline
\end{tabular}


Table 2. Medically related risk factors for HCV transmission

\begin{tabular}{|c|c|c|c|c|c|c|c|}
\hline \multirow{2}{*}{\multicolumn{2}{|c|}{ Medically related risk factors }} & \multicolumn{4}{|c|}{ HCV test result } & \multirow{3}{*}{$x^{2}$} & \multirow{3}{*}{$\mathrm{p}$-value } \\
\hline & & \multicolumn{2}{|c|}{ negative ( $\mathrm{N}=832$ ) } & \multicolumn{2}{|c|}{ positive $(\mathrm{N}=168)$} & & \\
\hline & & $\mathrm{n}$ & $\%$ & $\mathrm{n}$ & $\%$ & & \\
\hline \multirow{2}{*}{ Surgical treatment } & Yes & 116 & $51.6 \%$ & 109 & $48.4 \%$ & \multirow{2}{*}{207.9} & \multirow{2}{*}{0.000} \\
\hline & No & 716 & $92.4 \%$ & 59 & $7.6 \%$ & & \\
\hline \multicolumn{8}{|l|}{ Site of circumcision. } \\
\hline \multicolumn{2}{|l|}{ Private tools at home } & 24 & $100 \%$ & 0 & $0 \%$ & \multirow{4}{*}{145.6} & \multirow{4}{*}{0.000} \\
\hline \multicolumn{2}{|l|}{ Traditional healer } & 241 & $64.8 \%$ & 131 & $35.2 \%$ & & \\
\hline \multicolumn{2}{|l|}{ Public hospital } & 521 & $93.4 \%$ & 37 & $6.6 \%$ & & \\
\hline \multicolumn{2}{|l|}{ Not } & 46 & $100 \%$ & 0 & $0 \%$ & & \\
\hline \multirow{2}{*}{ History of blood transfusion } & Yes & 21 & $28 \%$ & 54 & $72 \%$ & \multirow{2}{*}{176.7} & \multirow{2}{*}{0.000} \\
\hline & No & 811 & $87.7 \%$ & 114 & $12.3 \%$ & & \\
\hline \multirow{2}{*}{ Injection by needle used before } & Yes & 96 & $47.3 \%$ & 107 & $52.7 \%$ & \multirow{2}{*}{234.9} & \multirow{2}{*}{0.000} \\
\hline & No & 736 & $92.3 \%$ & 61 & $7.7 \%$ & & \\
\hline \multirow{2}{*}{ Accidental wound with used needle } & Yes & 144 & $64.9 \%$ & 78 & $35.1 \%$ & \multirow{2}{*}{68.6} & \multirow{2}{*}{0.000} \\
\hline & No & 688 & $88.4 \%$ & 90 & $11.6 \%$ & & \\
\hline \multirow{2}{*}{ Parental antischistosomal treatment } & Yes & 12 & $19 \%$ & 51 & $81 \%$ & \multirow{2}{*}{197.9} & \multirow{2}{*}{0.000} \\
\hline & No & 820 & $87.5 \%$ & 117 & $12.5 \%$ & & \\
\hline \multirow{2}{*}{ Dental treatment } & Yes & 582 & $78 \%$ & 164 & $22 \%$ & \multirow{2}{*}{56.4} & \multirow{2}{*}{0.000} \\
\hline & No & 250 & $98.4 \%$ & 4 & $1.6 \%$ & & \\
\hline \multirow{2}{*}{ Hospitalization } & Yes & 97 & $51.3 \%$ & 92 & $48.7 \%$ & \multirow{2}{*}{169.4} & \multirow{2}{*}{0.000} \\
\hline & No & 735 & $90.6 \%$ & 76 & $9.4 \%$ & & \\
\hline
\end{tabular}

\section{DISCUSSION}

Chronic hepatitis $\mathrm{C}$ is a leading cause of end-stage liver disease, with a worldwide prevalence of up to $3 \%$. However, the number of new cases of chronic hepatitis $\mathrm{C}$ decreased substantially over the last decade, with well established risk factors for transmission of HCV (8). The recently published Egyptian Demographic Health Survey (EDHS) in 2009 was a national probability sample of the resident Egyptian population. This report estimated an overall anti-HCV antibody prevalence of $14.7 \%$ (1). The prevalence rate of HCV infection among the studied subjects was $16.8 \%$. It was more frequent in young and middle-aged adults and in males than females; these were in agreement with Luksamijarulkul et al. (9).

Blood donors are a low-risk population, usually presenting a lower prevalence than the open population (10). This study gives a highlight on $\mathrm{HCV}$ activity in Egypt. HCV prevalence varied considerably, from $8.8 \%$ to $26.6 \%$, in the reports of blood donors, owing primarily to differences in the age structure of the blood donors tested (1). The prevalence of HCV infection was found to be $0.37 \%$ in Singapore (11). Epidemiology Donor Study in different regions of the United States from January 1991 to December 1996 revealed that HCV prevalence decreased from $0.63 \%$ to $0.40 \%$ (12). The prevalence of anti-HCV among Kuwaiti national and non-Kuwaiti Arab blood donors was $0.8 \%$ and $5.4 \%$, respectively (13). The overall prevalence obtained from the study carried out on blood donors in the State of Puebla, Mexico was $0.84 \%$ (10).
In Egypt, $\mathrm{HCV}$ acquired a special importance, approximately one fifth (20\%) of Egyptian blood donors were anti-HCV positive. Egypt has higher rates of $\mathrm{HCV}$ than neighboring countries as well as other countries in the world with comparable socioeconomic conditions and hygienic standards for invasive medical, dental, or paramedical procedures (3). The prevalence rate of HCV infection among the same studied sample was $16.8 \%$. It was more frequent in young adults and middle-aged adult and in males than females; these were in agreement with Luksamijarulkul et al. (9).

A significant correlation was found between $\mathrm{HCV}$ test results and socio-demographic characteristics of the studied subjects. It was revealed that nearly one fifth $(21.6 \%)$ of low socio-economic level were positive.

The current study revealed that more than one third of subjects $(39.6 \%)$ who had jobs related to blood exposure were positive. $\mathrm{HCV}$ antibodies positive health care workers had been documented (5). The results of this study demonstrated that nearly half (52.7\%) of those subjected to a used needle were positive. In another study, contaminated and inadequately sterilized syringes and needles had resulted in outbreaks of hepatitis $\mathrm{C}$ among patients in clinics and physicians' offices (14). In Egypt, infection with hepatitis $C$ virus (HCV) has become the most important public health problem and viral hepatitis along with infection with Schistosoma mansoni is the major cause of chronic liver disease and liver cirrhosis (15). This study shows that $30.3 \%$ of HCV positive ones had received parenteral antischistosomal treatment, this was in accordance with Klenerman et al. (16) that a past injection treatment remains likely to be responsible for the high prevalence of $\mathrm{HCV}$ morbidity and 
Table 3. Behavioural related risk factors for HCV transmission

\begin{tabular}{|c|c|c|c|c|c|c|c|}
\hline \multirow{2}{*}{\multicolumn{2}{|c|}{ Behaviour related risk factors }} & \multicolumn{4}{|c|}{ HCV test results } & \multirow{3}{*}{$x^{2}$} & \multirow{3}{*}{ p-value } \\
\hline & & \multicolumn{2}{|c|}{ negative ( $\mathrm{N}=832$ ) } & \multicolumn{2}{|c|}{ positive ( $N=168)$} & & \\
\hline & & $\mathrm{n}$ & $\%$ & $\mathrm{n}$ & $\%$ & & \\
\hline \multirow{2}{*}{ Sexual relations } & Yes & 65 & $76.5 \%$ & 20 & $23.5 \%$ & \multirow{2}{*}{3.01} & \multirow{2}{*}{0.083} \\
\hline & No & 767 & $83.8 \%$ & 148 & $16.2 \%$ & & \\
\hline \multirow{2}{*}{ Contact with jaundiced patient } & Yes & 112 & $100 \%$ & 0 & $0 \%$ & \multirow{2}{*}{25.4} & \multirow{2}{*}{0.000} \\
\hline & No & 720 & $81.1 \%$ & 168 & $18.9 \%$ & & \\
\hline \multirow{2}{*}{ Tattoo } & Yes & 168 & $53.7 \%$ & 145 & $46.3 \%$ & \multirow{2}{*}{284.1} & \multirow{2}{*}{0.000} \\
\hline & No & 664 & $96.7 \%$ & 23 & $3.3 \%$ & & \\
\hline \multirow{2}{*}{ Drug abuse } & Yes & 31 & $52.5 \%$ & 28 & $47.5 \%$ & \multirow{2}{*}{42.1} & \multirow{2}{*}{0.000} \\
\hline & No & 801 & $85.1 \%$ & 140 & $14.9 \%$ & & \\
\hline \multirow{2}{*}{ Nail trimming } & Private tools & 776 & $83.8 \%$ & 150 & $16.2 \%$ & \multirow{2}{*}{3.2} & \multirow{2}{*}{0.072} \\
\hline & Common tools & 56 & $75.7 \%$ & 18 & $24.3 \%$ & & \\
\hline \multirow{3}{*}{ Ear piercing } & Private tools & 30 & $100 \%$ & 0 & $0 \%$ & \multirow{3}{*}{26.4} & \multirow{3}{*}{0.000} \\
\hline & Common tools & 102 & $69.9 \%$ & 44 & $30.1 \%$ & & \\
\hline & No & 700 & $85 \%$ & 124 & $15 \%$ & & \\
\hline \multirow{3}{*}{ Shaving } & Private tools & 107 & $70.9 \%$ & 44 & $29.1 \%$ & \multirow{3}{*}{20.1} & \multirow{3}{*}{0.000} \\
\hline & Common tools & 720 & $85.3 \%$ & 124 & $14.7 \%$ & & \\
\hline & No & 5 & $100 \%$ & 0 & $0 \%$ & & \\
\hline
\end{tabular}

may be largely responsible for the continued endemic transmission of HCV in Egypt. There was an association of positive anti-HCV test with history of previous parenteral treatment, hospital admission for clinical treatment, and acupuncture therapy. Mostafa et al. (17) identified the important role of injections in spreading HCV infection in this rural community.

It was found that dental treatment was a predominant risk factor for viral hepatitis transmission where one fifth (22\%) of subjects who had received dental treatment were positive. This was in agreement with Alam et al. (5) who found that people sharing unsterile medical or dental equipment are at high risk of contracting HCV. Traditional practices contributed to $\mathrm{HCV}$ transmission in Cameroon. All men were circumcised, but those who had undergone traditional (rather than medical) circumcision tended to be more likely to have been HCV infected. In a high-prevalence community of Egypt, male circumcision by an informal practitioner was also associated with HCV (7). Current study showed that nearly half (48.4\%) of those who had undergone surgical treatment were positive and nearly one third (35.2\%) of subjects circumcised by a traditional healer were positive. Nearly three quarters $(72 \%)$ of subjects with history of blood transfusion were positive. Studies carried out in the 1970 s suggested that about $7 \%$ of transfusion recipients developed non A non B hepatitis, and that up to $1 \%$ of blood units might contain causation virus. The introduction of anti- HCV screening has obviously reduced the transmission (18). Mostafa et al. (17) recommended screening of families of infected HCV subjects as an essential part of case management for early detection and their further management.

A low frequency of $\mathrm{HCV}$ infection $(0.004 \%$ to $0.0004 \%$ per unit transfused) continues to accompany blood transfusion due to the presence of infectious donors who are not detected by currently available antibody screening tests. Before any screening test was available, the risk of contracting the virus was 1 in 200 units transfused (19). Luksamijarulkul et al. (9) reported that history of receiving blood or blood products was related to $\mathrm{HCV}$ infection.

Results of the current study indicated that there was no statistical significant difference between sexual relations and $\mathrm{HCV}$ test results (only $11.9 \%$ of positive subjects had sexual relations) this was in disagreement with Luksamijarulkul et al. (9). Transmission of HCV by household contact and sexual activity appeared to be low (20).

The findings of this study indicated that $47.5 \%$ of drug abusers were positive. Consistent with these findings, Lee et al. (6) reported that major risk factor for $\mathrm{HCV}$ infections is parenteral exposure, especially among injecting drug users. In Europe, between $20 \%$ and $90 \%$ of new HCV cases have been identified among past or current injecting drug users (4). Very high rates of $\mathrm{HCV}$ antibody reactivity $(>70 \%)$ had been reported in injecting drug users and in hemophiliacs. Intermediate prevalence of 20 to $30 \%$ had been observed in patients receiving haemodialysis (21).

Results of the current study indicated that $46.3 \%$ of those who had tattoo were positive. This finding provides support for the postulate of Luksamijarulkul et al. (9) and Tripathi et al. (14). There was a limitation of this study. It was conducted on blood donors in general, thus it could not differentiate first time donor from a usual blood donor.

\section{CONCLUSION AND RECOMMENDATION}

It is required to carry out future community-based epidemiological studies also in other areas to determine the prevalence of HCV infection among Egyptians all over Egypt. Prevention is the only safeguard against spread of viral hepatitis infection, thus, careful screening of blood, blood products, and adequate 
sterilization of reusable surgical or dental instruments should be done. Professional and public health education and implementation of infection control practices in all health facilities is of utmost importance.

\section{Conflict of interest}

Contributors: All authors contributed substantially to the study conception and design, data collection and analysis, and drafting and revision of the article. All approved the final version to be published.

\section{REFERENCES}

1. Miller FD, Abu-Raddad LJ. Evidence of intense ongoing endemic transmission of hepatitis C virus in Egypt. Proc Natl Acad Sci U S A. 2010 Aug 17;107(33):14757-62.

2. Glynn SA, Kleinman SH, Wright DJ, Busch MP; NHLBI Retrovirus Epidemiology Donor Study. International application of the incidence rate/window period model. Transfusion. 2002 Aug;42(8):966-72.

3. Hepatitis C - global prevalence (update). Wkly Epidemiol Rec. 1999 Dec 10;74(49):425-7.

4. Merkinaite S, Lazarus JV, Gore C. Addressing HCV infection in Europe: reported, estimated and undiagnosed cases. Cent Eur J Public Health. 2008 Sep;16(3):106-10.

5. Alam MM, Zaidi SZ, Malik SA, Naeem A, Shaukat S, Sharif S, et al. Serology based disease status of Pakistani population infected with hepatitis B virus. BMC Infect Dis. 2007 Jun 27;7:64.

6. Lee HC, Ko NY, Lee NY, Chang CM, Ko WC. Seroprevalence of viral hepatitis and sexually transmitted disease among adults with recently diagnosed HIV infection in Southern Taiwan, 2000-2005: upsurge in hepatitis $\mathrm{C}$ virus infections among injection drug users. J Formos Med Assoc. 2008 May;107(5):404-11.

7. Pépin J, Lavoie M, Pybus OG, Pouillot R, Foupouapouognigni Y, Rousset D, et al. Risk factors for hepatitis $\mathrm{C}$ virus transmission in colonial Cameroon. Clin Infect Dis. 2010 Oct 1;51(7):768-76.

8. Maieron A, Metz-Gercek S, Hackl F, Luger C, Ziachehabi A, Strauss R, et al. Chronic hepatitis C in Austria, 1992-2006: genotype distribution and demographic factors. Euro Surveill. 2010 Feb 25;15(8):19492.
9. Luksamijarulkul P, Thammata N, Sujirarat D, Tiloklurs M. Hepatitis $\mathrm{C}$ virus infection among Thai blood donors: antibody prevalence, risk factors and development of risk screening form. Southeast Asian J Trop Med Public Health. 2004 Mar;35(1):147-54.

10. Sosa-Jurado F, Santos-López G, Guzmán-Flores B, Ruiz-Conde JI Meléndez-Mena D, Vargas-Maldonado MT, et al. Hepatitis C virus infection in blood donors from the state of Puebla, Mexico. Virol J. 2010 Jan $25 ; 7: 18$.

11. Wang JE. A study on the epidemiology of hepatitis C infection among blood donors in Singapore. J Public Health Med. 1995 Dec;17(4):387-91.

12. Glynn SA, Kleinman SH, Schreiber GB, Busch MP, Wright DJ, Smith JW, et al. Trends in incidence and prevalence of major transfusion-transmissible viral infections in US blood donors, 1991 to 1996. Retrovirus Epidemiology Donor Study (REDS). JAMA. 2000 Jul 12;284(2):229-35.

13. Ameen R, Sanad N, Al-Shemmari S, Siddique I, Chowdhury RI, AlHamdan S, et al. Prevalence of viral markers among first-time Arab blood donors in Kuwait. Transfusion. 2005 Dec;45(12):1973-80.

14. Tripathi AK, Khanna M, Gupta N, Chandra M. Low prevalence of hepatitis $\mathrm{B}$ virus and hepatitis $\mathrm{C}$ virus co-infection in patients with human immunodeficiency virus in Northern India. J Assoc Physicians India. 2007 Jun;55:429-31.

15. Halim AB, Garry RF, Dash S, Gerber MA. Effect of schistosomiasis and hepatitis on liver disease. Am J Trop Med Hyg. 1999 Jun;60(6):915-20.

16. Klenerman P, Lucas M, Barnes E, Harcourt G. Immunity to hepatitis C virus: stunned but not defeated. Microbes Infect. 2002 Jan;4(1):57-65.

17. Mostafa A, Taylor SM, el-Daly M, el-Hoseiny M, Bakr I, Arafa N, et al. Is the hepatitis $\mathrm{C}$ virus epidemic over in Egypt? Incidence and risk factors of new hepatitis C virus infections. Liver Int. 2010 Apr;30(4):560-6.

18. Schreiber GB, Busch MP, Kleinman SH, Korelitz JJ. The risk of transfusion-transmitted viral infections. The Retrovirus Epidemiology Donor Study. N Engl J Med. 1996 Jun 27;334(26):1685-90.

19. van der Poel CL. Hepatitis $C$ virus and blood transfusion: past and present risks. J Hepatol. 1999;31 Suppl 1:101-6.

20. EASL International Consensus Conference on hepatitis C. Paris, 26-27 February 1999. Consensus statement. J Hepatol. 1999;31 Suppl 1:3-8.

21. Alberti A, Boccato S, Vario A, Benvegnù L. Therapy of acute hepatitis C. Hepatology. 2002 Nov;36(5 Suppl 1):S195-200.

Received June 7, 2010 Accepted in revised form August 12, 2011 